\title{
The Clinical Breast Examination: A Useful Screening Tool?
}

Jennifer Lo

Follow this and additional works at: https://aah.org/jpcrr

Part of the Diagnosis Commons, Neoplasms Commons, Oncology Commons, Public Health Education and Promotion Commons, and the Women's Health Commons

\section{Recommended Citation}

Lo J. The clinical breast examination: a useful screening tool? J Patient Cent Res Rev. 2015;2:34-37. doi: 10.17294/2330-0698.1049

Published quarterly by Midwest-based health system Advocate Aurora Health and indexed in PubMed Central, the Journal of Patient-Centered Research and Reviews (JPCRR) is an open access, peer-reviewed medical journal focused on disseminating scholarly works devoted to improving patient-centered care practices, health outcomes, and the patient experience. 


\title{
The Clinical Breast Examination: A Useful Screening Tool?
}

\author{
Jennifer Lo, MD \\ Family Medicine Residency, Aurora St. Luke's Medical Center, Milwaukee, WI
}

\begin{abstract}
The standardization of the clinical breast examination as a screening tool for breast cancer has been a topic of controversy. Current recommendations vary significantly from organization to organization without consensus. There currently does not seem to be sufficient evidence regarding overall survival benefit of the clinical breast exam. However, as adjunct screening with mammography, it may help find earlier breast cancers and the up to $5-10 \%$ of cancers missed by mammography. The most appropriate standardized protocol may be that the clinical breast exam can be performed at the discretion of the provider and patient, with more inclination toward use in women in whom the exam carries greater sensitivity. (J Patient-Centered Res Rev. 2015;2:34-37.)
\end{abstract}

Keywords clinical breast exam, breast cancer screening

The clinical breast examination is a widely used practice in both clinical and academic settings. It has become a standard part of the annual preventive well-woman examination. How effective the clinical breast exam is as a screening tool, and the evidence supporting it, remains ambiguous. Currently, there are many recommendations regarding use of the clinical breast exam among various organizations, but no consensus.

\section{BACKGROUND}

Breast cancer is the most common noncutaneous form of cancer in women. The 10-year probability of developing breast cancer increases with age; on average, the lifetime risk of developing breast cancer is 1 in $8{ }^{1,2}$ Breast cancer is the second leading cause of cancer deaths in women, after lung cancer; $88 \%$ of cancer deaths occur in women older than 50 years of age. Breast cancer deaths have decreased by $28-34 \%$ from 1990 to 2010, a decrease that has been attributed both to improvements in breast cancer treatment and early detection. ${ }^{1}$

It is widely accepted that mammography is the mainstay in screening modalities for breast cancer, with digital preferred over film mammography due to its sensitivity in younger women. The sensitivity of

Correspondence: Jennifer Lo, MD, 8348 Washington Avenue, Racine, WI, 53406, T: 262-884-4000, F: 262-884-4177,

Email: Jennifer.y.lo@gmail.com screening mammography ranges from $72 \%$ to $80 \%{ }^{3}$ Mammography reduces the risk of dying from breast cancer by about $20-35 \%$ in women $50-60$ years of age. ${ }^{2,4}$ Breast cancer usually has no symptoms when the tumor is small and is easily cured. Mortality from breast cancer can be directly related to the stage at diagnosis, which is why there has been so much attention focused on breast cancer screening recommendations.

About two-thirds of women age 40 or older receive an annual clinical breast exam screening. ${ }^{5}$ It is estimated that $5-10 \%$ of breast cancers may be detected by clinical breast exam alone. ${ }^{5}$ However, the overall benefit in survival and outcomes with clinical breast exams has yet to be proved.

\section{CURRENT RECOMMENDATIONS}

Many organizations have issued recommendations regarding providers' use of the clinical breast exam as a screening tool for patients at average risk (Table $\left.1^{2,6-10}\right)$. However, recommendations among these organizations differ significantly, from insufficient evidence to recommend screening ${ }^{7,8}$ to screening aggressively beginning at age 20 and annually starting at age $40 .{ }^{9,10}$ The U.S. Preventive Services Task Force is in the process of updating its breast screening guidelines. Its most recent recommendation from 2009, an update from 2002, states there is insufficient evidence to recommend for or against clinical breast exams. ${ }^{6,7}$ The National Cancer Institute and the American Academy of Family 
Table 1. Summary of current recommendations for clinical breast examination screening ${ }^{2,6-10}$

\begin{tabular}{|c|c|}
\hline Organization & Recommendation \\
\hline $\begin{array}{l}\text { Canadian Task Force } \\
\text { on Periodic Health } \\
\text { Examination }\end{array}$ & Age 50-69, annually \\
\hline $\begin{array}{l}\text { National Comprehensive } \\
\text { Cancer Network }\end{array}$ & $\begin{array}{l}\text { Age } 25-39 \text {, every } 1-3 \text { years; } \\
\text { age } \geq 40 \text {, annually }\end{array}$ \\
\hline $\begin{array}{l}\text { American Academy of } \\
\text { Family Physicians }\end{array}$ & Insufficient evidence \\
\hline National Cancer Institute & No specific recommendations \\
\hline $\begin{array}{l}\text { U.S. Preventive Services } \\
\text { Task Force }\end{array}$ & $\begin{array}{l}\text { Insufficient evidence to } \\
\text { recommend for or against }\end{array}$ \\
\hline $\begin{array}{l}\text { American College } \\
\text { of Obstetricians and } \\
\text { Gynecologists }\end{array}$ & $\begin{array}{l}\text { Age } 20-39 \text {, every } 1-3 \text { years; } \\
\text { age } \geq 40 \text {, annually }\end{array}$ \\
\hline American Cancer Society & $\begin{array}{l}\text { Age } 20-39 \text {, every } 3 \text { years; } \\
\text { age } \geq 40 \text {, annually }\end{array}$ \\
\hline
\end{tabular}

Physicians have no specific recommendations. ${ }^{2,8}$ The American Cancer Society and the American College of Obstetricians and Gynecologists (ACOG) have the strictest screening guidelines, recommending a baseline screening at age 20. The ACOG updated its screening recommendations in 2011. . $^{2,9}$ The National Comprehensive Cancer Network and the Canadian Task Force on the Periodic Health Examination each recommend clinical breast exam every $1-3$ years from age 25 to 39 then annually at age $40-50$ and older. ${ }^{10}$

\section{CURRENT EVIDENCE}

A current search for evidence does not yield many new or recent studies to sway recommendation for or against screening. There are a few studies that have compared long-term outcomes using mammography alone versus mammography in conjunction with clinical breast exams. Most studies have shown no difference in outcome. However, there were more early-stage breast cancers found with dual screening. ${ }^{11}$ Perhaps the most referenced study is the randomized Canadian National Breast Screening Study-2 (CNBSS-2), which reported 13-year results in women 50-59 years of age. ${ }^{12}$ The study compared two groups of women who were recruited from January 1980 to March 1985. These women were followed by record linkage through December 1993 and by active breast cancer registry through June
1996. One group received annual mammography with a clinical breast exam, another received clinical breast exam alone. The results of the study concluded that yearly mammography with clinical breast exam detected considerably more lymph node-negative and small breast cancers but had no impact on mortality from breast cancer. This study also found that the sensitivity of the clinical breast exam was $54 \%$, one of the highest sensitivities reported thus far.

A published study by Bobo et al. looked at breast cancer screening findings reported to the National Breast and Cervical Cancer Early Detection Program from 1995 to 1998. ${ }^{11}$ This study of low-income women found that about $5.1 \%$ of abnormal clinical breast exams with normal mammography were later found by biopsy to be malignant, suggesting that these cancers may have been missed by mammography alone. Another $11.2 \%$ of cancers detected by clinical breast exam had missing mammography data. The average age of women in this study was 52.5 years, with about $10 \%$ of women younger than age 40 and $9 \%$ older than age 70 . Women with breast symptoms made up $18.9 \%$ of the records examined. Abnormal results were more common in this group than in asymptomatic women.

This study also reported a high number of abnormal clinical breast exams in women under 40 (14.1\%), which the study attributed to artifact as the detection program does not encourage screening for women that young. ${ }^{11}$ Both the inclusion of women with breast symptoms as well as the high number of abnormal breast exams in women under 40 may have skewed the results of this study to reflect a higher number of detected cancers. This study estimated a sensitivity of $58.8 \%$, specificity of $93.4 \%$ and positive predictive value of $4.3 \%$. Sensitivity decreased with age, whereas specificity and positive predictive value increased with age. ${ }^{11}$

A 2002 study from the Netherlands investigated the predictors of sensitivity in the clinical breast exam. The study reported sensitivity of the clinical breast exam to be, on average, $35 \%$, varying somewhat based on risk factors. ${ }^{5}$ The study examined women age 50 years or older and high-risk women age 40-49. Study participants were invited for a screening visit during 
which a trained nurse performed a clinical breast exam and a screening mammogram. Investigators reported that the strongest predictor of detection of cancer with clinical breast exam was tumor size. The highest sensitivity was observed in women 50-59 years of age, with sensitivity significantly lower in women $40-49$ years and those 80 years or older. Sensitivity also was higher among Asian and white women, women with lower body weight $(<135$ pounds) and women on hormone replacement therapy with estrogen and progesterone.

A 2005 review article on breast cancer screening by Elmore et al. reported sensitivities of clinical breast exams from community practices ranging from $28 \%$ to $36 \%{ }^{4}$

One study of interval breast cancers, defined as breast cancers discovered within 1 year of normal screening mammography, found that $16 \%$ of interval cancers were found during routine clinical breast exam performed by clinicians in asymptomatic women. ${ }^{3}$ The remainder were found by subsequent mammograms conducted on women who presented with a breast concern or complaint. Not surprisingly, the interval cancers were higher-stage, larger tumors and had more lymph node positivity than those with mammography screening-detected cancers. The factor that most influenced discovery was a patient having two or more breast concerns; the most often reported concerns were a breast lump and a personal and/or family history of breast cancer. ${ }^{3}$

The clinical breast exam itself is a relatively benign exam. Its potential harms stem from falsepositive results that can lead to consequences such as overdiagnosis, patient anxiety, pain from mammography compression and radiation exposure. It has been reported that after 10 years of screening, $50 \%$ of women will have at least one false-positive mammogram and $20 \%$ of women will have one falsepositive clinical breast exam. ${ }^{4}$

\section{DISCUSSION}

There continues to be ambiguous evidence regarding the use of the clinical breast exam as a screening tool. Any benefits in survival related to clinical breast exam, especially in women who are likely to be screened with mammography based on current recommendations, have yet to be seen. Most studies have shown no difference in outcome, suggesting that performing clinical breast exams on women who are already undergoing mammography prevents no additional deaths from breast cancer., ${ }^{211,12}$ There is, however, some evidence that clinical breast exams as an adjunct screening tool may help detect earlier cancers and interval cancers. Some studies have reported that the clinical breast exam may find some cancers initially missed by mammography. ${ }^{2}$

While clinical breast exam is not without risks, namely the consequences of false positives resulting in further testing, the exam in itself is relatively quick, easy to perform and benign.

The bigger picture may involve access to preventive care providers for any type of screening. One retrospective study of patients with newly diagnosed breast cancer reviewed the health care utilization patterns of patients with early breast cancer versus locally advanced breast cancer. ${ }^{13}$ While both groups had a similar number of contacts with the health care system, the early breast cancer group attended primary care visits at higher rates, received higher rates of breast imaging studies and were three times more likely to have received a clinical breast exam.

Research for breast screening is quite dynamic, and new evidence emerges frequently. In fact, a 25-year follow-up study from the CNBSS-2 preliminarily concluded that annual mammography for those age 40-59 years did not reduce mortality from breast cancer more than regular physical breast exam. ${ }^{14}$ It will be interesting to see if further studies supporting this finding emerge in the upcoming years, and how the myriad recommendations may change based on new findings.

\section{CONCLUSIONS}

Currently, it would be reasonable to conclude that a clinical breast examination may be done at the discretion of the provider and the patient in women at average risk. Presence of risk factors such as family or personal history of breast cancer and breast complaints as well as characteristics that suggest increased clinical breast exam sensitivity (e.g. age 
50-59 years, low body weight, Asian and Caucasian ethnicity, hormonal replacement therapy ${ }^{5}$ ) would be practical reasons to perform the clinical breast exam on a more regular basis. When the decision is uncertain, pending more evidence regarding the harm of unnecessary mammography, performing the clinical breast exam may be more favorable than refraining from doing so since there is a chance to detect early-stage breast cancer.

\section{Patient-Friendly Recap}

- Clinicians regularly examine their patients' breasts to check for lumps that may be cancerous.

- The authors report that undergoing this clinical breast examination has not resulted in any benefit to overall survival, and it may generate unnecessary tests.

- However, clinical breast exams can help detect a small percentage of cancers missed by mammography, especially in smaller women $50-59$ years of age.

- A clinical breast exam may be performed for any patient if she and her clinician agree, as it may detect early-stage breast cancer.

\section{Acknowledgment}

The author acknowledges Brenda Fay, MLIS, of Aurora Libraries for literature search assistance.

\section{Conflicts of Interest}

None.

\section{REFERENCES}

1. American Cancer Society. Breast Cancer Facts \& Figures 2013-2014. Atlanta, GA: American Cancer Society, 2013, pp. 1-37.

2. Tice JA, Kerlikowske K. Screening and prevention of breast cancer in primary care. Prim Care. 2009;36:533-58.

3. Carney PA, Steiner E, Goodrich ME, et al. Discovery of breast cancers within 1 year of normal screening mammogram: how are they found? Ann Fam Med. 2006;4:512-8.

4. Elmore JG, Armstrong K, Lehman CD, Fletcher SW. Screening for breast cancer. JAMA. 2005;293:1245-56.

5. Oestreicher N, White E, Lehman CD, Mandelson MT, Porter PL, Taplin SH. Predictors of sensitivity of clinical breast examination (CBE). Breast Cancer Res Treat. 2002;76:73-81.

6. Nelson HD, Tyne K, Naik A, et al. Screening for breast cancer: an update for the U.S. Preventive Services Task Force. Ann Intern Med. 2009;151:727-37.

7. U.S. Preventive Services Task Force. Screening for breast cancer. http://www.uspreventiveservicestaskforce.org/uspstf/ uspsbrca.htm. Accessed March 8, 2014.

8. Tria Tirona M. Breast cancer screening update. Am Fam Physician. 2013;87:274-8.

9. American College of Obstetricians and Gynecologists. Annual mammograms now recommended for women beginning at age 40 (July 20, 2011). https://www.acog.org/About_ACOG/ News_Room/News_Releases/2011/Annual_Mammograms Now_Recommended_for_Women_Beginning_at_Age_40. Accessed Jan. 28, 2014.

10. Susan G. Komen ${ }^{\circledR}$. Breast cancer screening recommendations for women at average risk. http://ww5.komen.org/BreastCancer/ GeneralRecommendations.html. Accessed Feb. 17, 2014.

11. Bobo JK, Lee NC, Thames SF. Findings from 752,081 clinical breast examinations reported to a national screening program from 1995 through 1998. J Natl Cancer Inst. 2000;92:971-6.

12. Miller AB, To T, Baines CJ, Wall C. Canadian National Breast Screening Study-2: 13-year results of a randomized trial in women aged 50-59 years. J Natl Cancer Inst. 2000;92:1490-9.

13. Carter TI, Reilly JJ. Missed opportunities: clinical antecedents in the diagnosis of advanced breast cancer. Ann Surg Oncol. 2012;19:2782-5.

14. Miller AB, Wall C, Baines CJ, Sun P, To T, Narod SA. Twenty five year follow-up for the breast cancer incidence and mortality of the Canadian National Breast Screening Study: randomised screening trial. BMJ. 2014;348:g366.

(C) 2015 Aurora Health Care, Inc. 